\title{
Gamut of NeWSPaper Prints in FunCtion of THE ENVIRONMENT
}

\author{
DOBRIC, E.; KUMPAR, D.; GOLUBOVIC, K. \& ZJAKIC, I.
}

Abstract: Light and gas fastness are two very important aspects of print quality. The aim of this proceeding is to determine light and pollutant impact on the gamut of prints through exposure of samples to artificial, glass filtered and direct sun-light, as well as common gas pollutants. Exposed samples were analysed by densitometric and spectrophotometric methods and statistically processed in order to determine the correlation between time and type of exposure and gamut changes. The results show a significant impact of combined direct sunlight and pollutants on prints. Beside the scientific aspect, these results could be used as guidelines for manufacturers and printers to improve the quality, while still maintaining low production costs.

Key words: newspaper print, consumables, light-fastness, gamut, environment
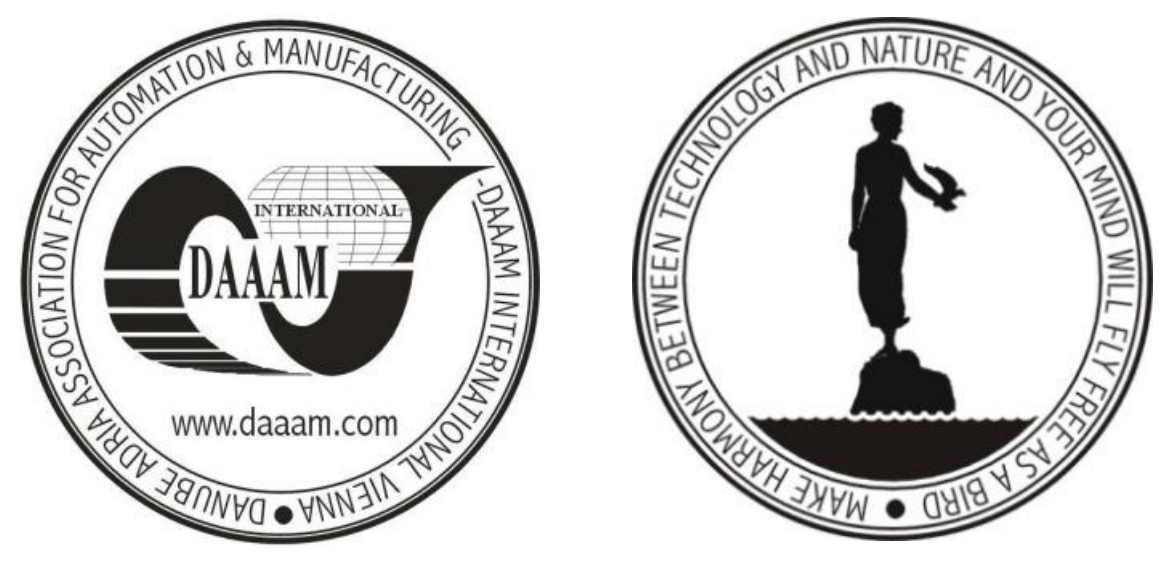

Authors' data: PhD. Student Dobric, E[ugen]; Dipl.-Ing. Kumpar, D[ejan]; PhD. Student Golubovic, K[ristijan]; Prof. Ass. Dr. Sc. Zjakic, I[gor], Univeristy of Zagreb, Faculty of Graphic Arts, Getaldiceva 2, 10000, Zagreb, Croatia, eugen.dobric@gmail.com, dejan.kumpar@24sata.hr, kristijan.golubovic@grf.hr, igor.zjakic@grf.hr

This Publication has to be referred as: Dobric, E[ugen]; Kumpar, D[ejan]; Golubovic, K[ristijan] \& Zjakic, I[gor] (2011). Gamut of Newspaper Prints in Function of the Environment, Chapter 08 in DAAAM International Scientific Book 2011, pp. 095-102, B. Katalinic (Ed.), Published by DAAAM International, ISBN 978-3-901509-84-1, ISSN 1726-9687, Vienna, Austria

DOI: $10.2507 /$ daaam.scibook.2011.08 


\section{Introduction}

Reader's purchasing power weakening due to the world economic crisis lead to the decrease of the newspaper circulation and forced publishers to use cheaper consumables (paper, ink, fountain solution additive etc.) with a goal of cutting production costs. Those cheaper consumables are on the very edge of giving satisfactory quality product. The widespread opinion is that offset print has a satisfactory high resistance in comparison to other widely spread printing technologies also used for newspaper print (for example digital methods (Dobric et al., 2009) - light-fastness, thermo-stability, humidity-fastness, gas pollutant fastness.

It is known that colour degradation is influenced by a number of different environment factors like temperature, relative humidity, light intensity and spectral distribution. Light-fastness describes how fast the product's quality degrades if exposed to light. Paper, as time passes looses fastness, becomes fragile and changes colouration. The degradation is influenced by the characteristics of paper and conditions in the environment. Aged paper is degraded by irreversible breaking of mechanical, chemical and optical characteristics. One of the examples of the environmental conditions is the air pollution (acidic gases) that has a negative effect on paper (Fellers et al., 1989). There are several studies of different laboratories that demonstrate the effect of $\mathrm{SO}_{2}$ and $\mathrm{NO}_{\mathrm{X}}$ on various papers (Begin et al., 1999; Daniel et al., 1990; Havermans, 1995; Iversen et al., 1991). The role of $\mathrm{O}_{3}$ which is the most important oxidant in the atmosphere is also very important and is connected to $\mathrm{NO}_{\mathrm{X}}$ emission from fossil fuel combustion. If $\mathrm{NO}_{\mathrm{X}}$ is presented to the sunlight, $\mathrm{O}_{3}$ is created as a result of photolysis of $\mathrm{NO}_{2}$. When $\mathrm{NO}_{\mathrm{X}}$ emissions are high, like in the urban areas, $\mathrm{O}_{3}$ gets consumed in a reaction with $\mathrm{NO}$. Contrary to $\mathrm{NO}_{\mathrm{X}}$, another pollutant $\mathrm{SO}_{2}$ concentration slowly decreases in urban air, and that is why there is much higher concentration of $\mathrm{NO}_{\mathrm{X}}$ and $\mathrm{O}_{3}$ than $\mathrm{SO}_{2}$ (Seinfeld et al., 1998). Some studies show that $\mathrm{NO}_{\mathrm{X}}$ and $\mathrm{O}_{3}$ increase the rate of deposition of $\mathrm{SO}_{2}$ on paper (Johansson et al., 1998). If the humidity is higher the deposition is even higher $\left(\mathrm{O}_{3}\right.$ efficient at moderate and $\mathrm{NO}_{\mathrm{X}}$ at high humidity). The trend that fresh paper initially adsorbs small amounts of $\mathrm{SO}_{2}$ while aged paper is completely in reactive towards it is clearly shown in some other studies while it doesn't react at any significant rate with pure cellulose (Atherton et al., 1973). The initial reaction on paper subjected to $\mathrm{SO}_{2}$ and $\mathrm{O}_{3}$ is the protonation of carboxylate groups on the fibre. As all the carboxylate groups in the aged paper are protonated, that is the reason why it is inreactive towards the pollutants (Johansson et al., 2000).

This proceeding shows how the modern consumables behave in different printing product usage conditions by gamut overview of the prints aged in natural environment. Samples are printed on newsprint machine Manroland Geoman. Results of the research, beside the scientific contribution in understanding the environment impacts on size of the gamut, tonal range and print quality, can be used to show newspaper publishers, their print service companies and consumables producers how low can they go in cutting production costs and gaining still acceptable quality. 


\section{Experimental}

Offset is a printing technique called "flat" as the printing and non-printing areas on a printing plate are placed virtually on a same level. Printing areas are oleophilic and hydrophobic, they attract ink and repel water, while non-printing areas are completely different - hydrophilic and oleophobic, attract water and repel ink. This effect is conditioned by physical phenomenon on the contact areas. Dampening system covers areas with thin layer of fountain solution. Fountain solution consists of water and additives which are added for reducing surface tension and in that way producing conditions for dampening solution to be equally applied non-printing areas. Offset is a printing technique that demands perfect tuning up of chemical and physical consumable's characteristics and printing process, so the product of a satisfactory quality could be produced (Kipphan, 2001; Zjakic 2007). Manroland Geoman is a newspaper CMYK offset rotation, especially efficient while printing large and equable circulations, Broadsheet 450x300 mm format, paper role width $1200 \mathrm{~mm}$, max speed of 38.500 pieces per hour on one tower.

Sample prints were made as instructed by ANSI standard IT8.7/4 which contains 1617 different colour fields. This standard defines colour combinations for subtractive synthesis and is not optimised for any printing process in particular but is robust enough for all general uses like classic offset CMYK print. It is intended for spectrophotometric analysis which gives information for $2 \mathrm{D}$ and $3 \mathrm{D}$ gamut visualisations in perceptual colour space. Samples were printed on $42,5 \mathrm{~g} / \mathrm{m} 2$ Norske Skog "Nornews" uncoated newspaper made in Austrian Bruck factory (it consists of 92\% pulp which is recycled raw cellulose fibber, $7 \%$ is moisture and $1 \%$ sizing agents) with Sun Chemical lower tack printing ink. Samples were exposed indoor with daily and artificial light in indoor atmosphere (Sample 1), sunlight through window in indoor atmosphere (Sample 2) and direct sunlight and gas pollutant impact outdoor (Sample 3).

Gamut volumes were measured immediately after print and afterwards in 1 and 7 days interval. While research was conducted, the samples were kept in a box in a closed, dark space. After the exposure, measurements made by spectrophotometer were systematized, analysed by computer and statistically processed for each field. The conversion from CIE XYZ to CIE $L^{*} a^{*} b^{*}$ system was done for better presentation of sample's 3D gamut in a three-dimensional colour system. Visualisations were made for light intensity $L^{*} 50$.

\section{Results and discussions}

As already stated before in this work, colour degradation is influenced by a number of different environment factors like temperature, relative humidity, impact of gas pollutants, which are systematized in charts for a period of time in which ageing was conducted. 
Dobric, E.; Kumpar, D.; Golubovic, K. \& Zjakic, I.: Gamut of Newspaper Prints...

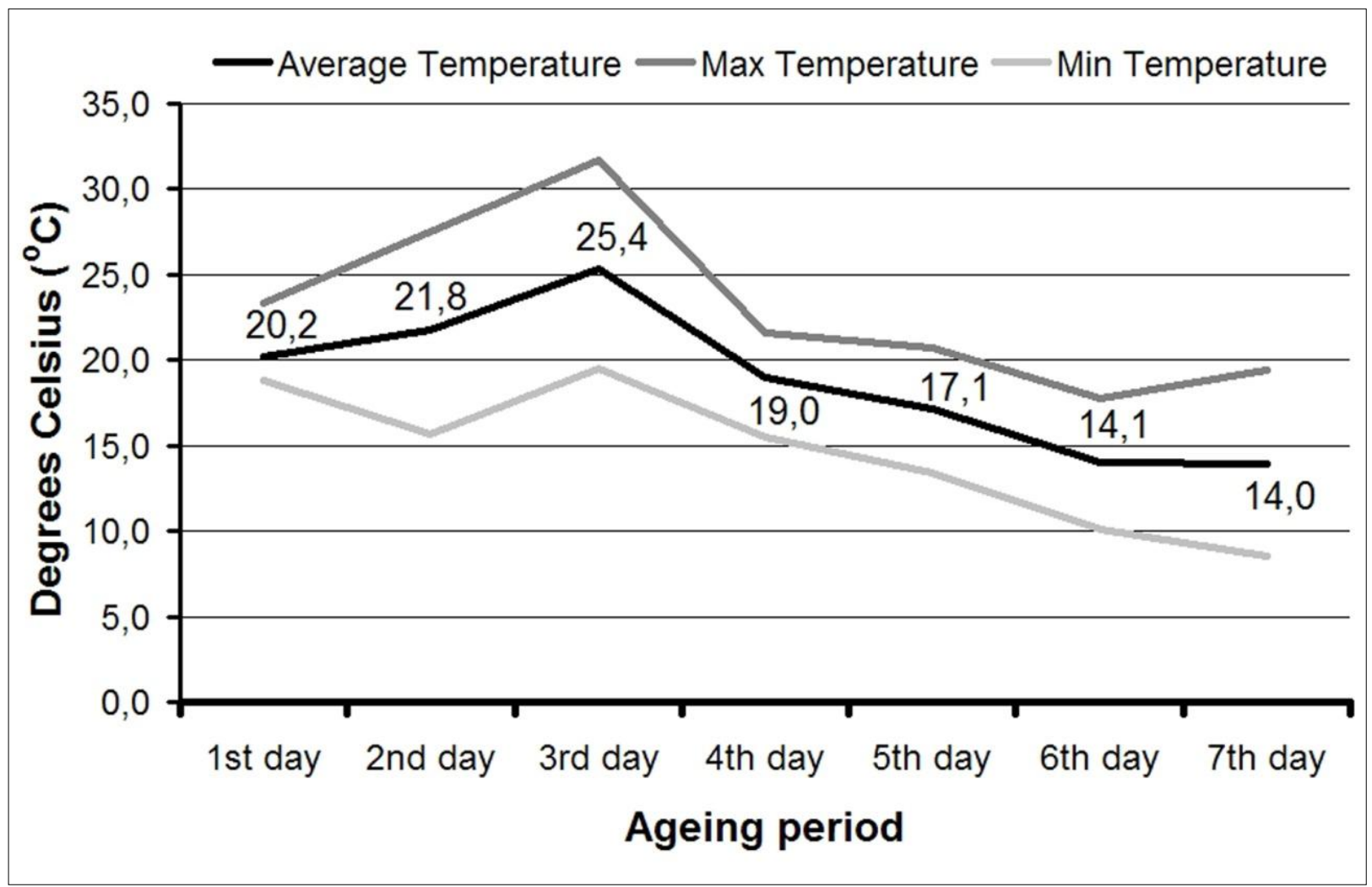

Fig. 1. Temperature chart for a 7 days ageing period (end of August)

Average daily temperature in a seven days period of ageing varied from $25,4^{\circ} \mathrm{C}$ to $14,0^{\circ} \mathrm{C}$ or more precisely the highest measured temperature at this time was $31,7^{\circ} \mathrm{C}$ and lowest $8,5^{\circ} \mathrm{C}$ (figure 1 ).

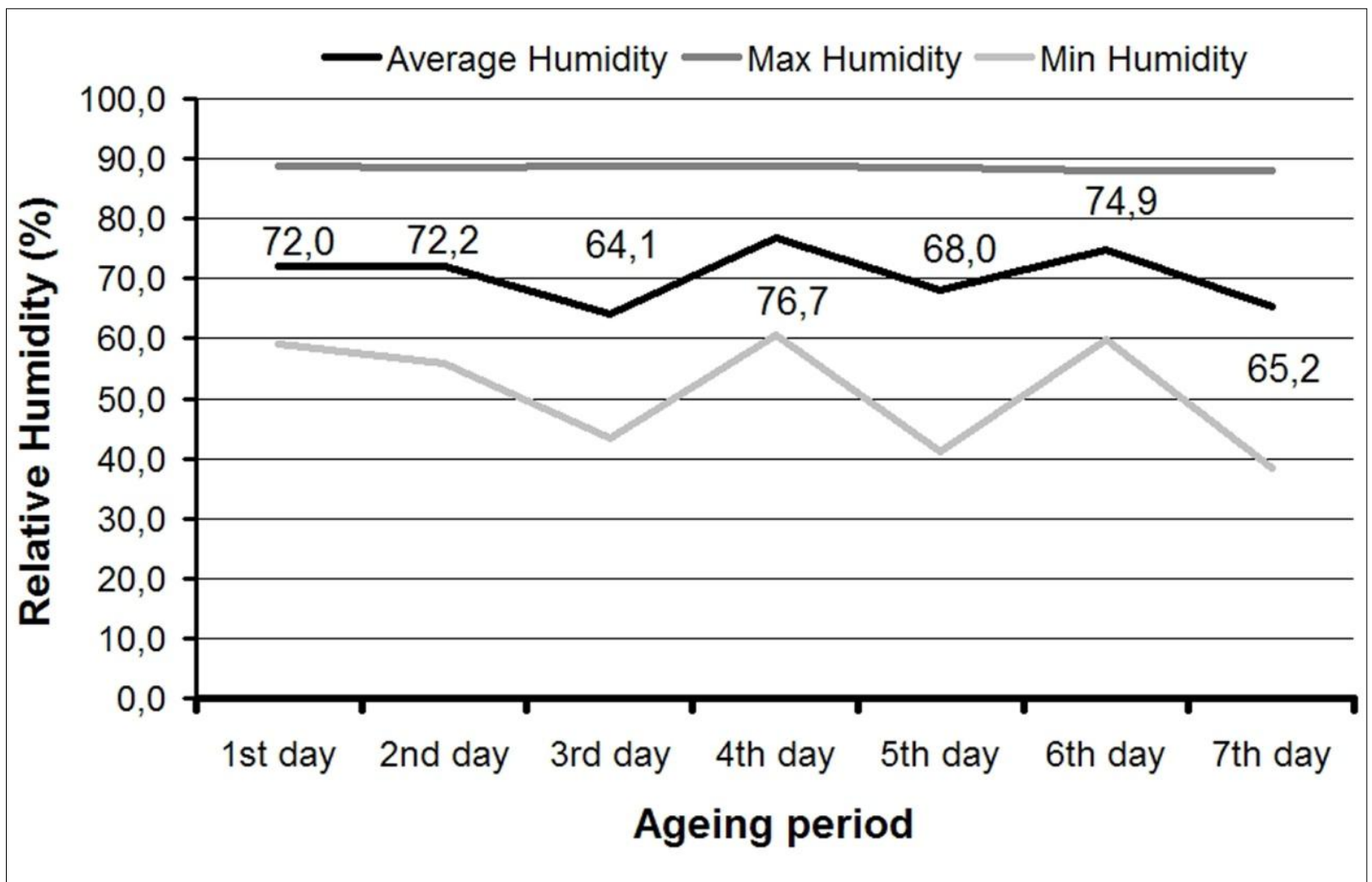

Fig. 2. Relative humidity chart for a 7 days ageing period (end of August) 
Average relative humidity was fluctuating from $65,2 \%$ to $74,9 \%$ or $88,9 \%$ highest and 38,4\% lowest recorded relative humidity (figure 2).

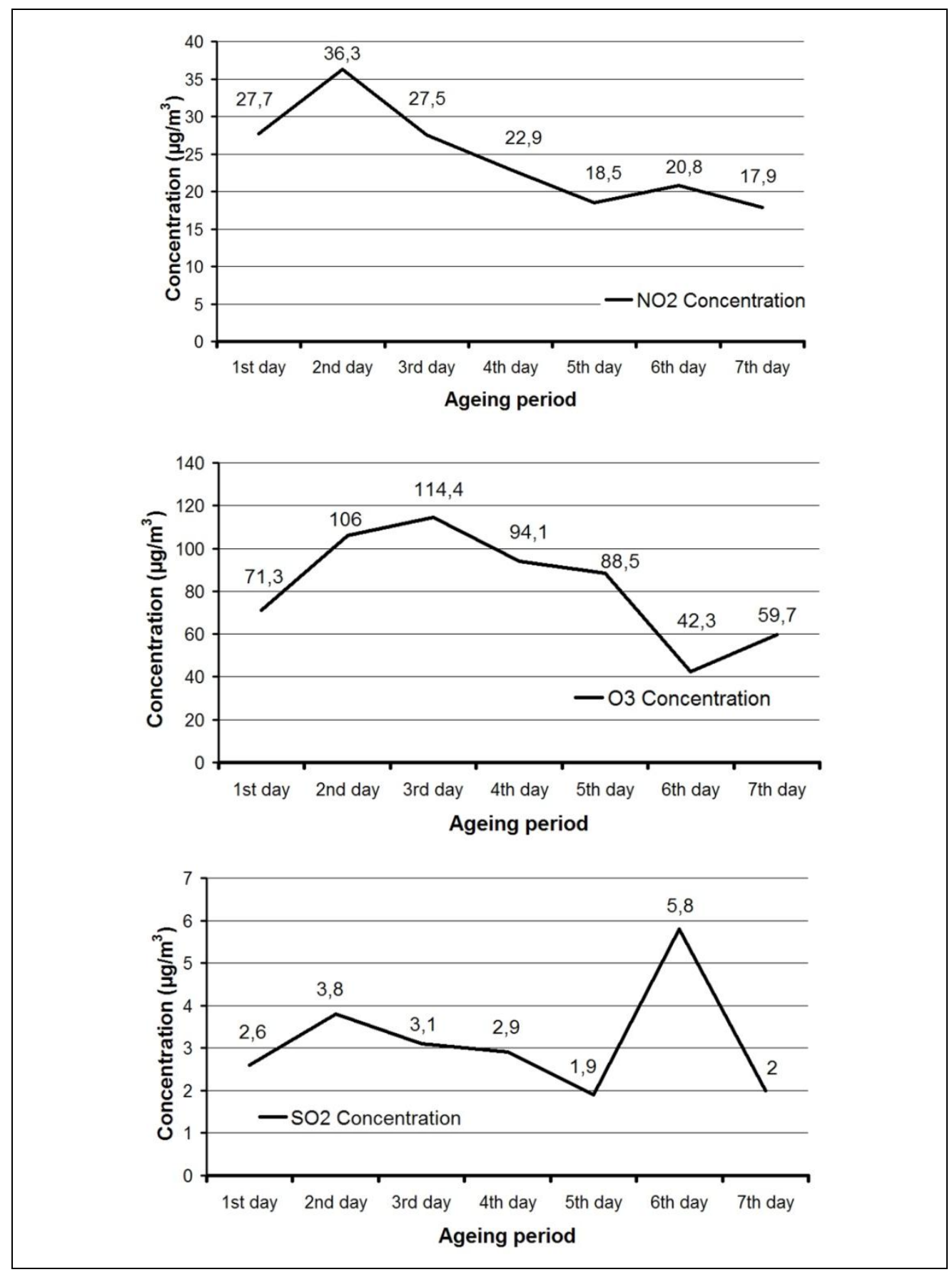

Fig. 3. Nitrogen dioxide, Ozone and Sulphur dioxide concentration for a 7 days ageing period

Highest Nitrogen dioxide concentration was recorded in the second day at 36,3 $\mu \mathrm{g} / \mathrm{m}^{3}$ and lowest in the last day $17,9 \mu \mathrm{g} / \mathrm{m}^{3}$ (figure 3 ). Ozone concentration, the most important oxidant in the atmosphere, was between $114,4 \mu \mathrm{g} / \mathrm{m}^{3}$ and $42,3 \mu \mathrm{g} / \mathrm{m}^{3}$ (figure 3). Highest Sulphur dioxide concentration was recorded at $5,8 \mu \mathrm{g} / \mathrm{m}^{3}$ and the lowest at $1,9 \mu \mathrm{g} / \mathrm{m}^{3}$ in the same period of time (figure 3 ).

Media used for information distribution is limited by quantity of information it can represent. Limited gamut represents total information range of colour, tone, density, saturation, lightness that media can reproduce. For objective evaluation of 
print quality, ANSI values were measured on samples of different combinations of colour values for subtractive synthesis. Obtained information is converted by computer for the construction of $3 \mathrm{D}$ cubic colour units.

\begin{tabular}{|c|c|c|c|}
\hline $\begin{array}{c}\text { Printing } \\
\text { substrate }\end{array}$ & $\begin{array}{c}\text { Immediately } \\
\text { after print }\end{array}$ & $\begin{array}{c}\text { 1 day } \\
\text { of ageing }\end{array}$ & $\begin{array}{c}7 \text { day } \\
\text { of ageing }\end{array}$ \\
\hline Sample 1 & 159.621 & 159.378 & 159.468 \\
\hline Sample 2 & 159.621 & 159.754 & 154.929 \\
\hline Sample 3 & 159.621 & 146.671 & 133.134 \\
\hline
\end{tabular}

Tab. 1. Gamut volumes V CIE L*a*b* CCU (Manroland Geoman)

Values of gamut 1, 2 and 3 were gained from samples printed in the same printing machine but measured immediately after print or 1 and 7 days of exposure. If analyzed, results clearly show that volume of Sample 1 gamut (table 1), exposed indoor in the indoor atmosphere on daily and artificial light, got reduced after 1 day for 243 gamut units, but after 7 days of exposure reduced for just 90 units more if compared to 1 day exposure. Total reduction of gamut volume for Sample 1 was 153 units or V CIE L*a*b* CCU got smaller for $0,095 \%$ after 7 days, and that is almost insignificant reduction. On Figure 4 a three-dimensional and two-dimensional gamut of the print is shown. Indoor where the light is filtrated through glass window, spectre of visible light contains wavelengths higher than $340 \mathrm{~nm}$.

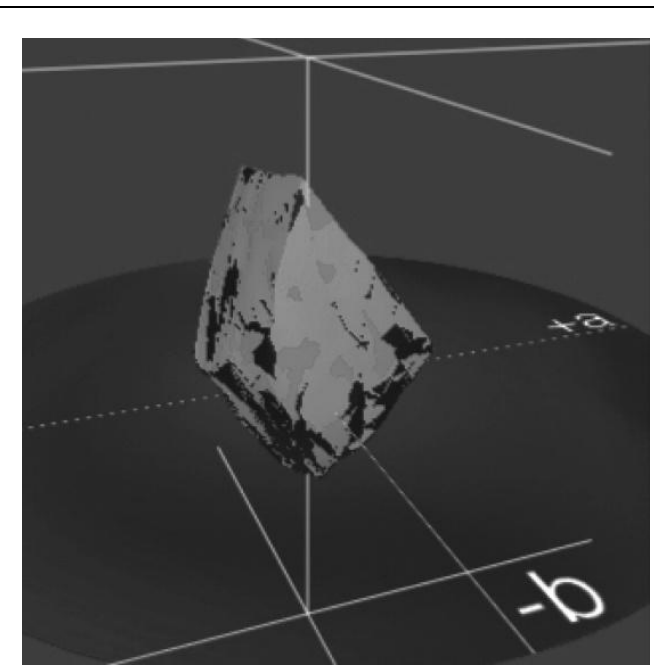

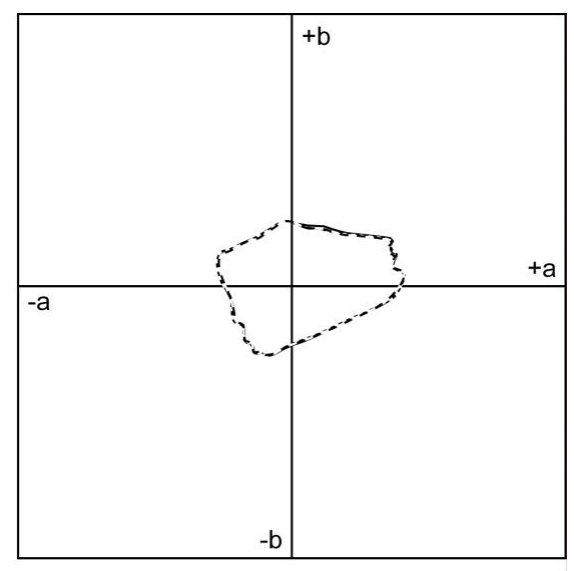

L 50

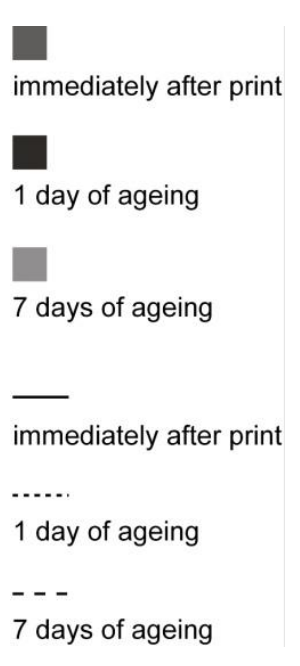

Fig. 4. Print gamut 3D and 2D (Manroland Geoman, Sample 1)

More visible results are gained by analysis of Sample 2 (Table 1), exposed to sunlight through glass window that limits the light to wavelengths over $340 \mathrm{~nm}$. It's gamut volume has increased by 133 gamut units after 1 day exposure (we attribute this effect to acceptable error of measuring device), but total decrease eventually was 4692 units or V CIE L*a*b* CCU is smaller for 2,939\% after 7 days exposure. On Figure 5 three-dimensional and two-dimensional print gamut is shown on which it can be clearly seen that gamut has decreased in blue-purple area. 


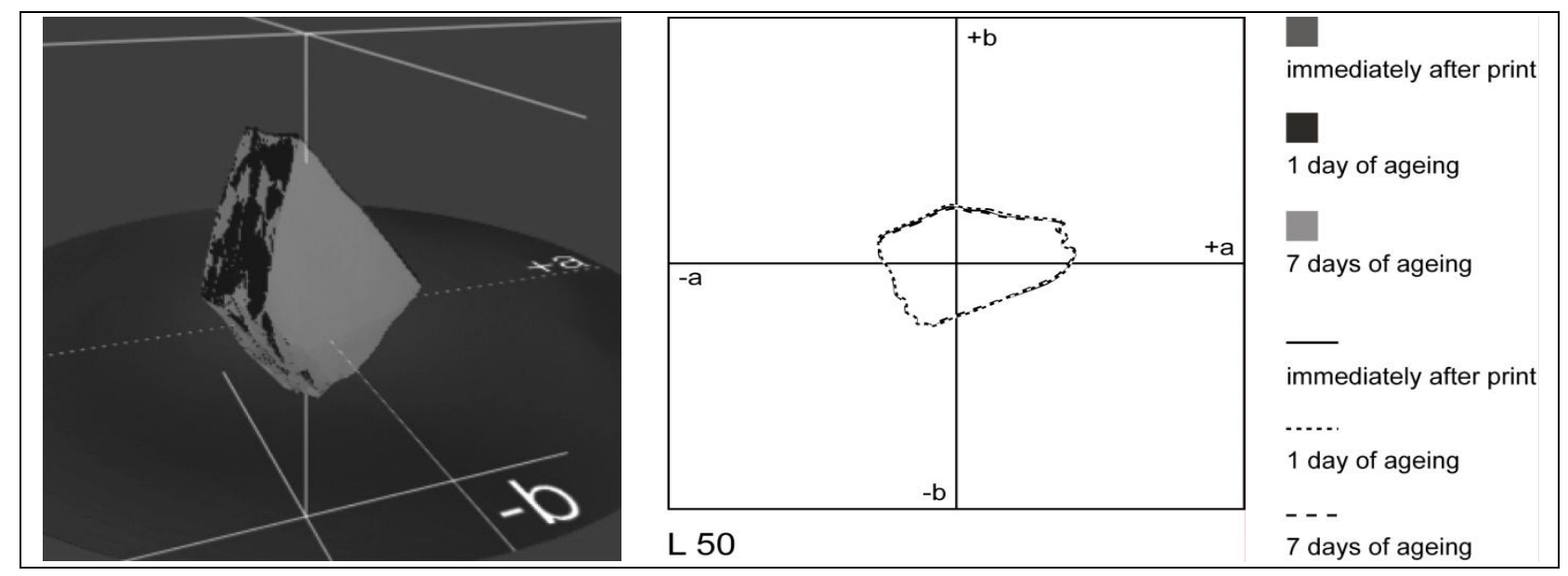

Fig. 5. Print gamut 3D and 2D (Manroland Geoman, Sample 2)

Most significant change was observed by analysis of Sample 3 (Table 1), exposed to direct sunlight and outside atmosphere impact. Gamut volume for this sample has decreased for 12.950 units already after the first day of exposure, while after 7 days it further decreased for 26.487 volume units or V CIE L*a*b* CCU was smaller for $16,594 \%$. It can be seen on Figure 6, three-dimensional and twodimensional print gamut visualization, that gamut got reduced in blue-purple area even more significantly than on Sample 2.
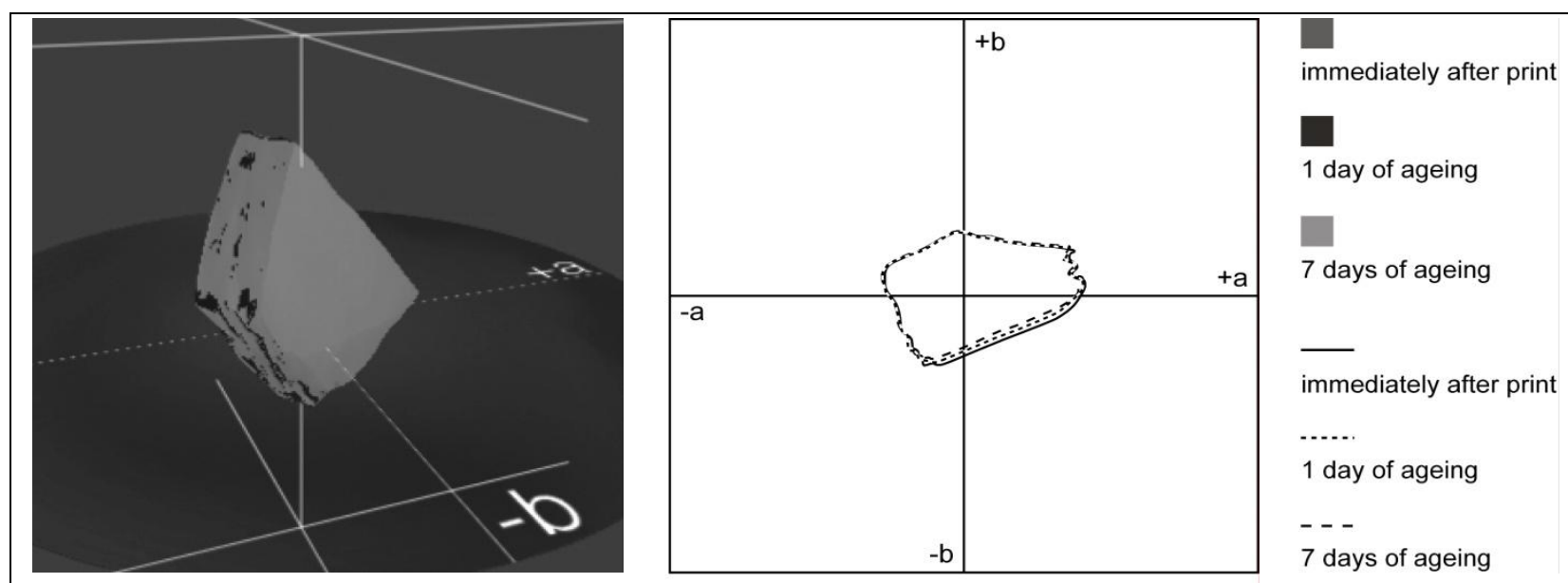

L 50

Fig. 6. Print Gamut 3D and 2D (Manroland Geoman, Sample 3)

\section{Conclusion}

After the analysis of gained results the next conclusions can be made:

Sample 1 prints didn't show significant changes, so it could be easily concluded that quality of newspaper product, whose value for reader usually last no longer than one week, will not decrease if kept for seven days indoor, out of direct sun-light and not under the direct impact of gas pollutants. Sample 2 prints also didn't show any

significant changes so the conclusion could be that newspaper product exposed in shop window (glass limits the ultraviolet radiation in sun-light spectrum) won't show an important quality decrease for the reader. Reader won't be able to see the 
difference between freshly printed newspaper product and the one a week old. Sample 3 prints have shown a significant gamut volume decrease in blue-purple colour area. This effect can be attributed to the exposure to direct sun-light with full light spectrum, where the most dangerous ultraviolet radiation in combination with gas pollutant ozone had a greatest impact on print quality degradation.

Gained results, beside the scientific contribution in the domain of understanding and explaining the environmental conditions on the print quality and gamut size, have also an applicable value. Further research will include different newsprint substrates with variable quantity or recycled fibres, as well as different printing inks, in order to determine the general correlation of lighting and pollutants with the print durability.

\section{References}

Atherton J.B.; Hudson F.L.; Hockey J.A. (1973). The effect of temperature, light and some transitional metal ions on the sorption of sulphur dioxide by paper. $J$. Appl. Chem. Biotechnol. 23, pp 407-414

Begin P. et al. (1999). The Effect of Air Pollutants on Paper Stability. Restaurator vol. 20, (Jan. 1999.), pp 1-21, ISSN 0034-5806

Daniel F.; Flieder F.; Leclerc F. (1990). The Effects of Pollution on Deacidified Paper Restaurator vol. 11-3, pp 179-207, ISSN 0034-5806

Dobric, E.; Bolanca, Z.; Sindic, I. (2009). Gamut of Ink Jet Prints in Function of the Enviroment, Chapter 68 in DAAAM International Scientific Book 2009, pp. 703-712, B. Katalinic (Ed.), Published by DAAAM International, Vienna, Austria, ISBN 978-3-901509-69-8, ISSN 1726-9687

Fellers C. et al. (1989). Ageing/Degradation of paper, A literature survey, Report No.

1E, The Swedish R\&D Project for Paper Preservation, Stockholm, ISSN 02845636

Havermans J. (1995). Effects of Air Pollutants on the Accelerated Ageing of Cellulose-based Materials. Restaurator vol. 16, pp 209-233, ISSN 0034-5806

Iversen T.; Kolar J. (1991). Effects of nitrogen dioxide on paper, Report No. 5, The Swedish R\&D Project for Paper Preservation, Stockholm, ISSN 0284-5636

Johansson A. et al. (1998). Uptake of Air Pollutants by Paper, Report No. 8, The Swedish R\&D Project for Paper Preserv., Stockholm, pp 117-137, ISSN 00345806

Johansson, A.; Lennholm, H.; (2000). Influences of $\mathrm{SO}_{2}$ and $\mathrm{O}_{3}$ on the ageing of paper investigated by in situ diffuse reflectance FTIR and time-resolved trace gas analysis, Applied Surface Science, 161, 2 March 2000, pp 163-169, ISSN 0169-4332

Kipphan, H.; (2001). Handbook of Print Media: technologies and production methods, Springer, New York, ISBN 3-540-67326-1

Seinfeld J.H.; Pandis S.N. (1998). Atmospheric Chemistry and Physics From Air Pollution to Climate Change, Wiley, New York, ISBN 0-471-17816-0

Zjakic I. (2007.) Upravljanje kvalitetom ofsetnog tiska, HSN, Zagreb, ISBN-13: 9789531691451 